\title{
THE LEAN SIX SIGMA APPROACH FOR PROCESS IMPROVEMENT: A CASE STUDY IN A HIGH QUALITY TUSCANY WINERY
}

\author{
Riccardo Bettini, Alessandro Giorgetti, Enrico Cini, Paolo Citti
}

\section{Introduction}

Agricultural and agrofood production processes are actually resource intensive processes. These processes bear a high level of environmental effects associated with life cycles of the agrofood chain, such as primary energy consumption, water exploitation, and global warming [Beccali 2009]. In addition the sector needs to improve its economic efficiency in order to survive in the face of intensifying global market competitiveness. Agricultural and agrofood production processes are often not standardized nor optimized, and each specific producer may employ individualized processes. Therefore, in many cases, current agricultural productions use suboptimized processes.

Evidence suggests that many agricultural processes could yield better performance, in terms of resource consumption, cost saving and an improvement in product quality. In this context a practical application of the Lean Six Sigma (LSS) method is presented in this paper. However it is not the authors' purpose to offer a universally suitable solution to critical aspects of agricultural processes. The objective is to illustrate how it is possible to track expensive, but hidden flaws in agricultural productive processes, and subsequently determine the best way to resolve the problems through a structured, fact based method, such as LSS. In fact, through LSS, it is possible to identify the areas of inefficiency and failures and then remove the possible causes in order to improve the overall quality of the process.

The LSS method was initially applied to improve manufacturing industry processes. In the last few years, however, companies have successfully applied LSS to make improvements in various different sec-

Paper received 24.12.2009; accepted 02.03.2010

R. Bettini, E. Cini, Dipartimento di Ingegneria Agraria e Forestale - DIAF, Università di Firenze, Piazzale Cascine 15, 50144 Firenze, Italy.

A. Giorgetti, P. Citti, Dipartimento di Meccanica e Tecnologie Industriali - DMTI, Università di Firenze, via Santa Marta 3, 50139 Firenze, Italy. E-mail: alex.giorgetti@unifi.it. tors [Brady 2006]. These examples demonstrate the potential of the LSS method and the generality of its approach. Considering that some of the most powerful LSS Tools were first used in Agriculture to improve yield (e.g. Fisher Design of Experiment and Analysis of Variance), at present, the applications of LSS in the agriculture context are still very few [Tylutki 2002; Tylutki 2004; Guo 2008].

\section{Lean Six Sigma method}

The LSS is a rigorous and systematic methodology, which uses information and statistical analyses to measure and improve the performance of processes. LSS is a highly disciplined method that helps to focus on developing near-perfect products and services [Citti 2004; Breyfogle 1999]. The development of LSS is based on the combination of tools from both Lean Manufacturing and Six Sigma [George 2003; Devane 2004] (Fig. 1). In particular Lean Manufacturing focuses mainly on speed and waste reduction connected to non-value-added activities. Traditional Six Sigma focuses on quality improvement and reduction of waste connected to process variability [Goh 2004; Harry 2000; Raisinghani 2005]. When these methods

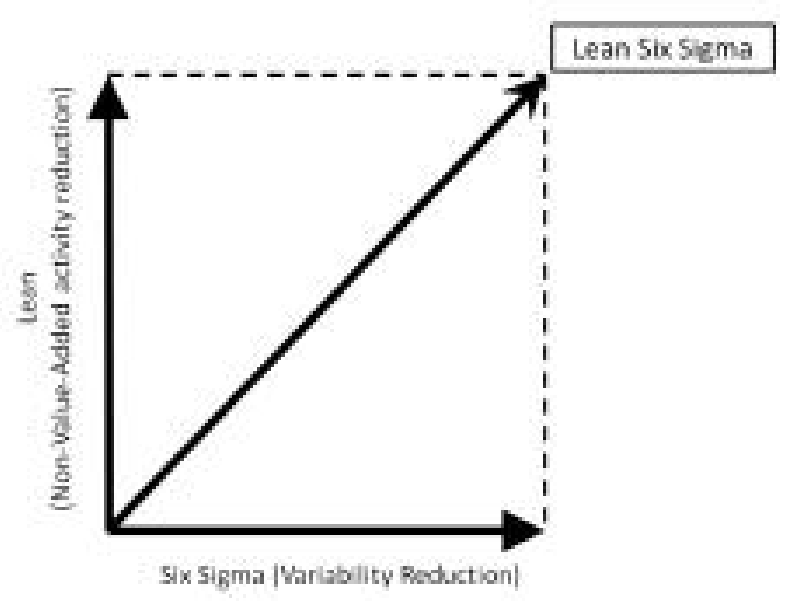

Fig. 1 - LLS: the integration of Lean and Six Sigma methodologies. 
are combined, they result is a higher quality process, which is faster and consumes fewer resources. In fact Lean Manufacturing and Six Sigma are synergistic approaches that reduce waste and improve processes [Breyfogle 2001]. The two methodologies are explained extensively in scientific literature [Brady 2006; Pyzdek 2003; Harry 2000; Ohno 1988]. In the present paper only the main characteristics of LSS are summarized.

Lean Six Sigma uses a problem-solving algorithm called DMAIC. This stands for Define, Measure, Analyze, Improve and Control [Citti 2008; Giorgetti 2009] (Fig. 2). DMAIC has proven itself to be one of the most effective problem solving methods because it assists in the usage of data to:

- Understand the nature and extent of the problem;

- Identify root causes of the problem;

- Find solutions that evidence shows are linked to the causes;

- Establish procedures for maintaining the solutions even after the project is completed.

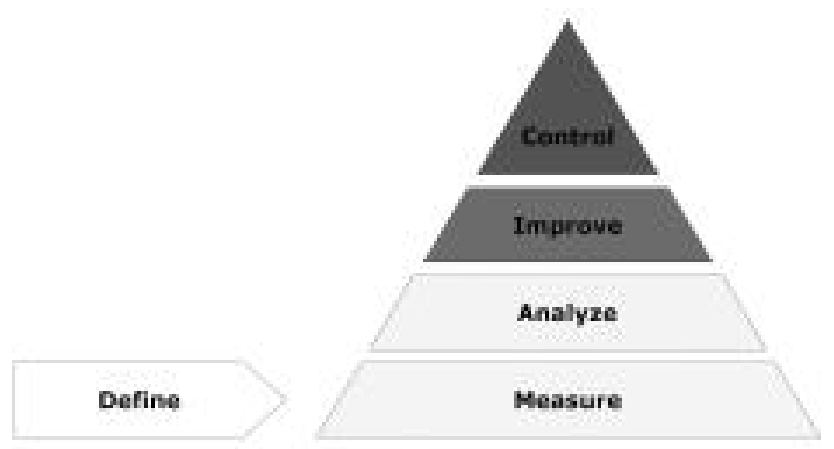

Fig. 2 - the DMAIC Algorithm used in LSS Project.

"Define" is the phase in which project goals and boundaries are defined, and the problem to be solved is identified. In this phase, the goal is to pinpoint the location or source of the problem as precisely as possible by building a factual understanding of existing process conditions and issues. This knowledge assists in narrowing the range of potential causes to be investigated in the "Analyze" phase.
The "Measure" phase is the heart of LSS. In this phase, the existing measurement system is evaluated, the process is observed, data is gathered and the process is mapped. Having stratified the data in the baseline performance, it detects the location or the source of the problems by building a factual understanding of the existing process' conditions and problems, which will help to focus the problem statement.

The purpose of the "Analyze" phase, is to make sense of all the information and data collected in the Measure phase. The data is used to confirm the source of delays, waste, and poor quality. In this phase theories of root causes are developed, then subsequently confirmed with data, and finally the root causes of the problem are identified. The verified causes form the basis for solutions in the "Improve" phase.

The purpose of Improve is to make changes in the process that reduce defects, waste or cost. In this phase, many possible solutions are identified and developed, involving the review of existing Best Practices to determine if any may be adapted to the current situation, the development of criteria for selecting a solution, piloting the chosen solution, and planning for full-scale implementation.

In the "Control" phase, the results are checked and a long term strategy is planned, in order to maintain the improvement accomplished. Control is necessary to make sure that the solution is correct and sustainable over the time.

\section{Materials and Methods}

\subsection{Introduction to the process}

The example of LSS implementation described below was chosen for its simplicity and completeness among many projects developed in an Italian, highquality winery. The example of LSS implementation presented in this paper is focused on the procedure for transferring liquid housed in the cellar. In fact, in winemaking plants it is necessary to move conspicuous amounts of liquid many times. The product is partitioned in lots and stored in tanks to allow for efficient management. Every lot needs to be moved many

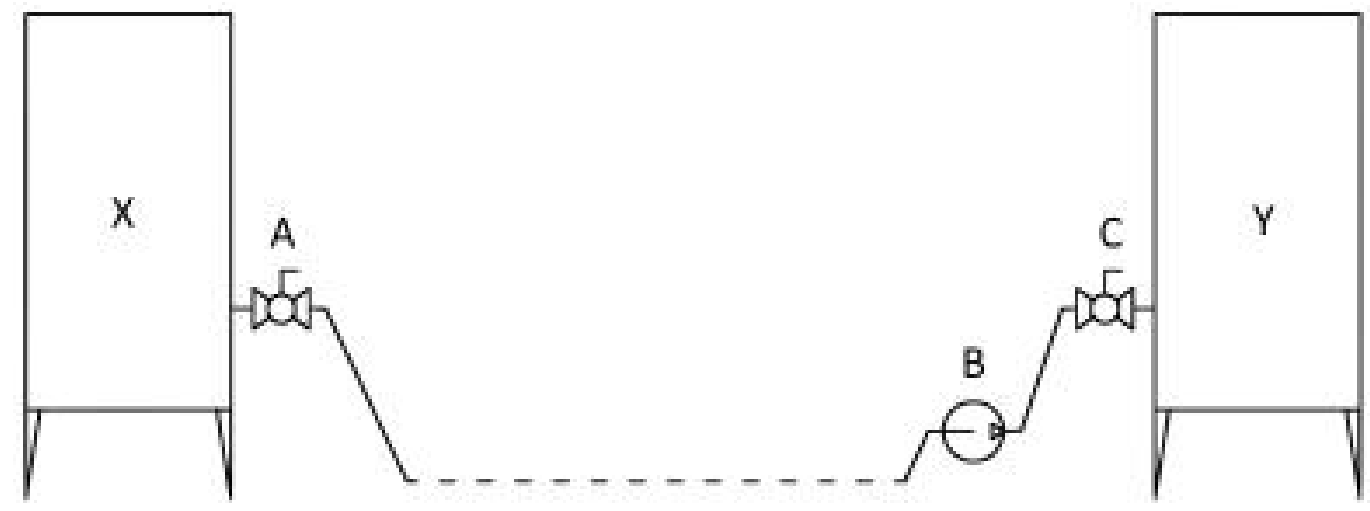

Fig. 3 - Traditional cellar layout: $X=$ Output tank; $Y=I n p u t$ tank; $A, C=$ Tap; $B=$ Pump. 
times between tanks before the finishing and bottling process. Transferring the liquid is usually done with pumps and pipes, as is shown in Figure 3.

In the example shown below, the cellar layout is flat and tanks are positioned at the same level. This configuration creates the problem of collecting residual liquid in the flat running piping below the pump level (as shown as a dashed line in Fig. 3) at the conclusion of each liquid transfer session. As a matter of fact, pumps are unable to pump liquid out if the section of piping is not filled with liquid.

The classic way to solve this problem is to place the pump near the input tank (Y) and lift manually the pipe from output tank $(\mathrm{X})$ to input tank $(\mathrm{Y})$ while the pipe is emptied by the pump, in order to eliminate the siphon and avoid an inrush of air. The second part of the pipe, between the pump and the input tank, is then disconnected from the tank and emptied in a bin that will be added to the tank manually.

At first inspection, the result of the classic transfer operation seems quite good when the advantages are compared to the disadvantages. The transfer of ten thousand liters of wine requires some extra work, but ends with only a puddle of wasted product on the ground. Also this procedure is not necessary every time. When it is possible, other transfers can be made without having to discharge the pipeline. For these reasons the product loss seems negligible. The classic piping discharge procedure does not appear to be as critical, and therefore its implementation does not seem necessary if we trust these observations alone.

\subsection{LSS way.}

The application of the LSS method to the same case bring us to different conclusions. First of all, a more objective evaluation of the importance of this problem is required. First, observations are made, leaving an accurate quantification of the following phases of the project:

1 -In the cellar of the considered factory there are 130 tanks, with a total capacity of 1.3 million liters. Considering 130 tanks, and the same number of product lots, and assuming the need to move each lot ten times for every production cycle (that is equivalent to one year), a total of 1300 transfer operations are required every production cycle. As a result, there are 650 opportunities per productive cycle occurring for a loss of product, given that in the $50 \%$ of the operations the pipeline discharged is needed.

2 -The lost quantity of product with the current procedure is about 10 liters per movement. The movement is needed 650 times and so a total amount of 6,500 liters of product is lost with an estimated cost of $65,000 €$ per production cycle.

3 -Consider that a 50 meter long pipe with a 65 millimeters inner diameter contains about 165 liters of product. The empty pipeline weighs about 100 kilograms, and the total weight of the full pipe is between 250 and 300 kilograms, a weight that is difficult to be lifted manually, even if it is lifted in sections.

4 -The time needed for each discharge operation could be estimated to be about 10 minutes; that equates to a hundred working hours per production cycle.

The critical nature of the transfer process and the potential waste incurred mandates deeper analysis, and measurements are needed to verify the initial observations. The following characteristics need to be quantified:

- The wasted product per discharging operation;

- The number of discharging operations in a productive cycle;

- The time needed to discharge the pipeline manually.

The estimate of lost product is calculated by the measurement of the residual product left inside the pipeline after the discharging process. When the pipeline then is disassembled and washed, the residual product left inside will be wasted. The best way to collect and measure the product left seems to be washing the pipeline with water, collecting the washing effluent and measuring its total volume.

A sample of the washing effluent should be taken and its color intensity is measured. The method used to determine color intensity is to sum optical densities, measured with a spectrophotometer at 420, 520 and 620 nanometers wavelength. The obtained value is then compared with values obtained by samples of the same product at known dilutions.

The relationship that allows to determinate the product loss volume is the following:

$$
V_{p}=C_{p} V_{a}
$$

where $\mathrm{V}_{\mathrm{p}}$ is the product loss volume, $\mathrm{V}_{\mathrm{a}}$ is the total volume of washing effluent and $\mathrm{C}_{\mathrm{p}}$ is:

$$
C_{p}=\frac{V_{\text {sat }}}{V_{\text {hat }}}
$$

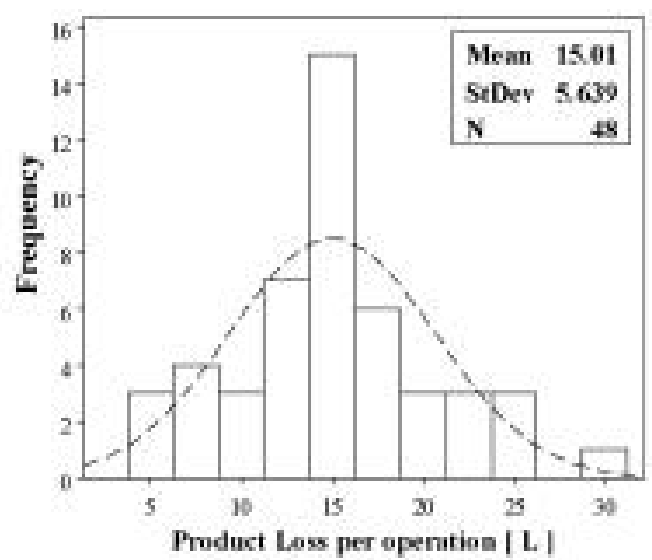

Fig. 4 - Histogram of product lost during the transfer of the liquid in the cellar. 
with $\mathrm{V}_{\text {tot }}$ the total volume of fluid and $\mathrm{V}_{\text {lost }}$ the volume lost in washing effluent.

The results obtained by the analysis of 48 samples are shown in Figure 4. The mean of lost product is approximately 15 liters and the standard deviation is quite high at about 5.6 liters. This variability is related mainly to the complex relationship between the volume of lost product and many different factors, such as the pipeline length and the degree of attention used in the manual discharge procedure. However, considering Figure 4, it is possible to conclude that the sample mean is an acceptable approximation for the lost product, noting that the same care is taken at every moment of the production cycle and there is the same probability of using long or short pipelines. These assumptions were made as there is no logical and experimental evidence to account for some of the differences during the production cycle, and by making such assumptions, it is possible to extend the result to the whole production cycle.

The number of loss occurrences is determined by having workers record daily the number of discharging operations and the total number of transferring operations. The ratio between these values is called Loss Index $\left(\mathrm{L}_{\mathrm{i}}\right)$, and is defined as:

$$
L_{y}=\frac{O_{p}}{O_{2}}
$$

where, $\mathrm{O}_{p}$ is the Number of daily pipeline discharging operations and $\mathrm{O}_{t}$ is the Number of daily transferring operations.

Also in this instance it is not necessary to extend the analysis to the whole production cycle. There is no stage of production where it appears to be necessary to discharge pipelines more often than in other stages, so there are no special causes in a production cycle that can generate a different behavior of $\mathrm{L}_{\mathrm{i}}$. For this reason the Loss Index can be extended to the whole production cycle. The values of $\mathrm{L}_{\mathrm{i}}$, obtained by a 30 days data collection, are shown in Figure 5.

By estimating the Loss Index it is possible to cal-

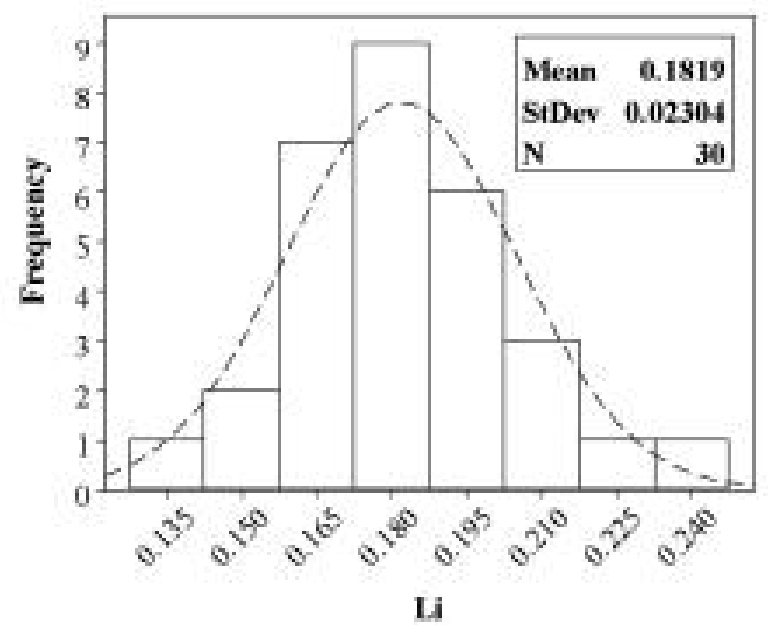

Fig. 5 - Histogram of the Loss Index obtained with 30 days data.

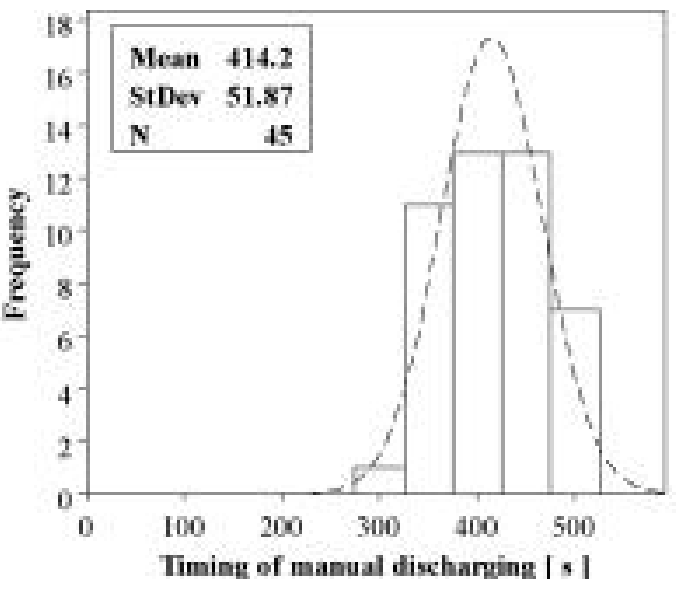

Fig. 6 - Histogram of time needed for the manual discharging of the pipeline.

culate the total occurrences resulting in a loss in the whole production cycle. This calculation requires the total amount of transfer operations during the production cycle. It is impossible to know that number until the current cycle is completed. In any event, the cycle's historical data can be relied upon, as there were no changes in production procedures and in the process between these cycles. From past cycle registrations, 2200 transfer operations per production cycle were found. Using this value in the calculations, 400 loss occurrences per production cycle are obtained and the total product losses are quantified at 6,000 liters per production cycle. Compared with the total cycle production, quantified at 1.3 million of liters, the product losses caused by the analyzed procedure are about $0.46 \%$.

The timing of the manual discharge of the pipeline has been estimated considering 45 operations, with different operators on various pipeline lengths. In this case too, the results are considered to be applicable to the whole production cycle, because of reasons discussed above. Data in Figure 6 show the mean of measured time for manual discharging is 415 seconds (about 7 minutes).

\section{Results and Discussion}

The result of the quantitative analysis discussed above highlights the importance of this process as a critical point and the importance of finding a solution.

The solution must follow at least one of the following directives:

- The reduction of number of events generating a loss;

- The loss reduction per event;

- The reduction of discharging time and hardness of work.

The first target is clearly not attainable, as discharging occurs for mandatory reasons, such as sanitary purposes or product incompatibility. 


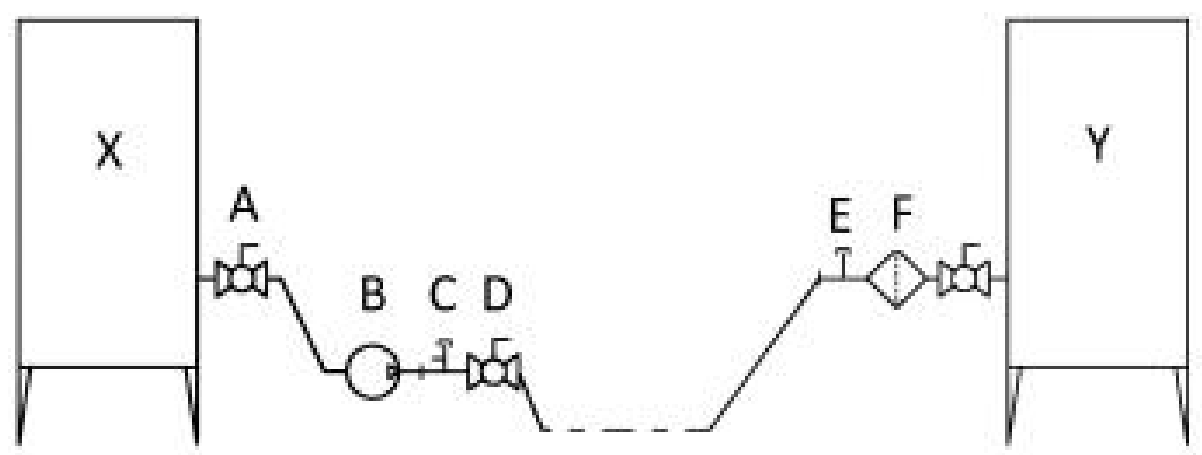

Fig. 7 - Improved cellar layout: $\mathrm{X}=$ output tank; $\mathrm{Y}=$ input tank; $\mathrm{A}, \mathrm{D}=$ taps; $\mathrm{B}=$ pump; $\mathrm{C}=$ sphere insertion hatchway with propeller input; $\mathrm{E}=$ =sphere recovery hatchway; $\mathrm{F}=$ filter

Prior to implementing a project, the boundaries imposed by the producer must be considered:

- No modifications on cellar layout;

- No modification on tanks;

- No bulky equipment obstructing the passage between tank's rows.

One possible solution is to discharge the pipeline using a rubber sphere. In fact operators could effectively "push out" the liquid from the pipeline sliding inside a sphere and pushing it with a proper fluid. This sphere must be flexible and of a suitable diameter.

A second possible solution is to suspend the pipeline to form a descending path from the output tank to the pump, avoiding the possibility of forming a siphon configuration. This solution is theoretically feasible, but not at all practical, because of the temporary character of each pipeline. In addition a flying pipeline running through the cellar could be an obstruction for workers and machinery.

The first idea does not seem to have the greater difficulties associated with the latter idea, and therefore, the first method was chosen.

Before thinking of the practical realization of the improvement solution, it is necessary to be conscious of problems related to this new procedure:

- The sphere cannot pass by the pump. It is a necessity to have a pump somewhere between input and output tanks;

- The sphere has to be inserted inside the pipeline without disassembling it;

- The sphere must be prevented from entering the tank at the end of discharging operation;

- It is necessary to choose a suitable fluid to propel the sphere. Gases appear to be better than liquids because the risk of mixing with the product is reduced. However some gases, such as carbon dioxide, are sometimes miscible with the product.

A new layout, solving the problems discussed is shown in Figure 7. In order to remedy the first problem, the position of the pump must be altered. The new layout, with the pump placed very near to the output tank, allows the first part of the pipeline, between output tank and pump, to discharge automatically. The use of a short link avoids the siphon config- uration of piping on the first part of the line. As the height of the bottom of the tank is greater than the height of the pump, we have a strictly descending link that will discharge itself automatically. It is then possible to insert the sphere after the pump to discharge the remaining part of the line. A tap is required to avoid the reflux of the product, while the sphere insertion hatchway is open. This is caused by the differential between atmospheric pressure and hydrostatic pressure of the liquid inside the input tank. After the sphere is inserted inside the line, it is forced through the pipe by a propeller.

In the analyzed winery there is a nitrogen generator and a distribution circuit around the cellar, which is also used for other operations. Nitrogen is a good choice, because it has a low solubility in the wine, and has no effect on it. Theoretically, it is possible to also use pressurized air, however, this could adversely affect the quality of the product, due to the oxygen content. In the presented case the Nitrogen has been chosen, despite the higher cost of production and pressurization of this propeller.

A very coarse filter is placed at the end of pipeline. It will produce a very low flow reduction, but will prevent the sphere from entering the input tank.

The new procedure's operations can be summarized as follows:

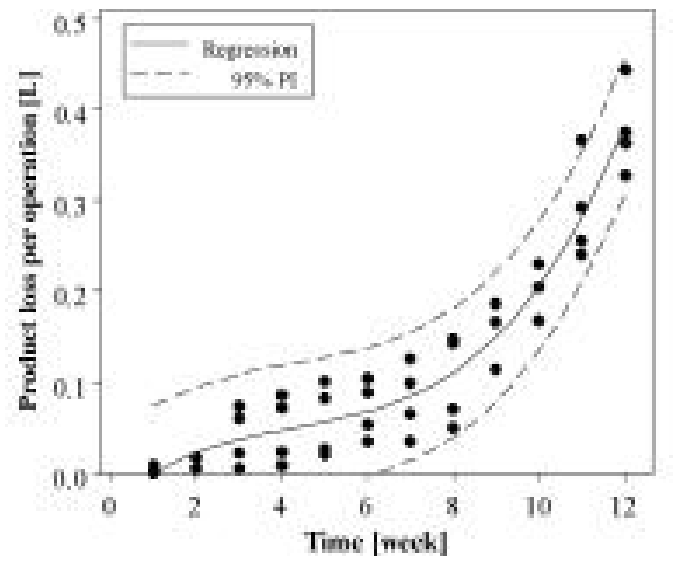

Fig. 8 - Regression analysis and Prediction Interval (PI) of measured losses trend of pumping lines. 


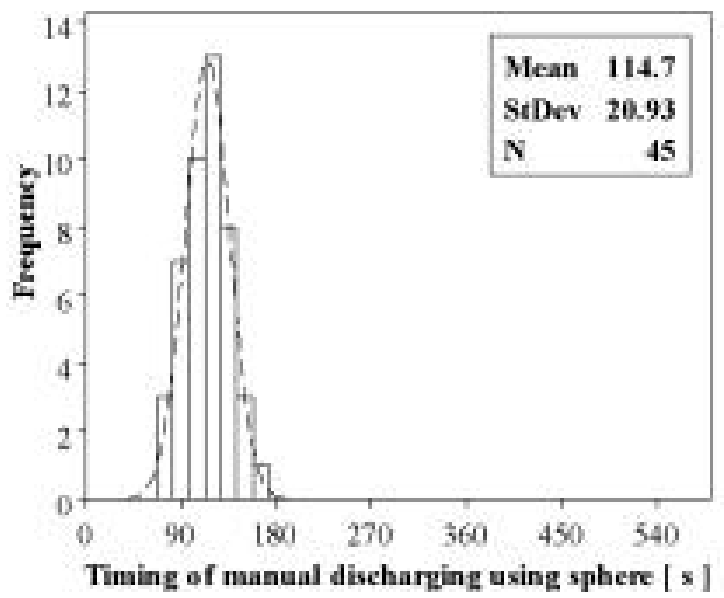

Fig. 9 - Histogram of time needed for the manual discharging of the pipeline after the improvement

1 -Close the tap D and turn off the pump B;

2 -Open hatchway $\mathrm{C}$ and insert the sphere;

3 -Open nitrogen inlet and open the tap D;

4 -Once the sphere arrives to filter $\mathrm{F}$, close input tank's own tap, then close nitrogen inlet;

5 -Open hatchway E and take off the sphere.

The control applied to this new procedure, in order to maintain desired results, is based on the check of the sphere integrity. The trend of losses for 12 weeks has been measured on many lines and the wear of the sphere caused by rubbing against interior piping walls has been registered. As shown in Figure 8, losses trend rises rapidly after eight weeks of use in our plant. So the sphere has to be substituted every 10 weeks to maintain a good process performance.

Testing this new procedure with the methods explained above, we found the following results (the data was collected for 12 weeks and used to estimate the production cycle performance):

- No product was found in the washing effluent. The only significant loss of product was generated by the volume of the pipe between the filter and the tank's tap, which is about 0.3 liters per movement (120 liters per production cycle);

- Time needed for discharging is lowered to only about 2 minutes, as shown in Figure 9;

- The overall savings due to improved process are estimated in $47,500 €$ per production cycle;

- The one-off cost for the implementation is $2,000 €$ (400€ per pumping line).

The results obtained (Tab. 1) show the positive economic impact of the implementation, resulting from a very small investment. It is possible to reach annual production improvements and economic benefits that far outweigh the initial investment. The presented LSS project describes how specific hidden waste can be significantly reduced through the use of a structured scientific approach. The project's savings is consistent and demonstrate the power of the LSS approach in driving process and performance improvement in an agricultural and agrofood context.

\section{Conclusions}

This paper shows the development of a LSS project to improve the performance of the procedure for transferring liquid used in the cellar during the winemaking process in an Italian, high-quality winery. The aim is to show how it could be possible to improve agricultural production processes using a structured, systematic methodology such as LSS. The DMAIC algorithm permits to follow a clear and safe path from focus on the critical aspect, the analysis and development of corrective initiative, up to the verification of results and the maintenance of the improved process. The LSS methodology assists the study of the problem and assists in reaching the goal through the development of a modified process where all decisions are based on data and facts. The results obtained are important in terms of waste reduction, bearing greater economic efficiency, and increasing safety for employees.

\begin{tabular}{|c|c|c|c|c|c|c|c|}
\hline & $\begin{array}{c}\text { Loss of time } \\
\text { for pipeline } \\
\text { discharge }\end{array}$ & $\begin{array}{c}\text { Loss rate of time for } \\
\text { pipeline discharge by } \\
\text { total working time in } \\
\text { cellars }\end{array}$ & $\begin{array}{c}\text { Operator cost } \\
\text { for } \\
\text { discharging } \\
\text { pipelines }\end{array}$ & $\begin{array}{c}\text { Loss of } \\
\text { product }\end{array}$ & $\begin{array}{c}\text { Loss rate } \\
\text { of } \\
\text { product }\end{array}$ & $\begin{array}{c}\text { Loss of selling } \\
\text { opportunity } \\
\text { due to product } \\
\text { loss }\end{array}$ & $\begin{array}{l}\text { Production } \\
\text { value }\end{array}$ \\
\hline $\begin{array}{c}\text { Baseline } \\
\text { Performance }\end{array}$ & $46.7 \mathrm{~h}$ & $2.33 \%$ & $840.60 €$ & $6000 \mathrm{~L}$ & $0.46 \%$ & $48000 €$ & $10400 \mathrm{k} €$ \\
\hline $\begin{array}{c}\text { Improved } \\
\text { Performance }\end{array}$ & $13.3 \mathrm{~h}$ & $0.66 \%$ & $239.40 €$ & $120 \mathrm{~L}$ & $0.01 \%$ & $960 €$ & $10447 \mathrm{k} €$ \\
\hline Improvement & $-33.4 \mathrm{~h}$ & $-1.67 \%$ & $-601.20 €$ & $-5880 \mathrm{~L}$ & $-0.45 \%$ & $-47040 €$ & $+47 k €$ \\
\hline
\end{tabular}

TABLE 1 - Quantitative analysis of the results per productive cycle (the total cycle production is 1.3 million liters). 
Modern agriculture has all the components of heavy industry namely: production, marketing, procurement and logistics. So it will be useful for this sector to have a reduction of waste, an increase in quality control, better pricing, and better logistics. These steps are clearly required for modern agriculture to meet the growing demands of quality food standards and increased attention to the consumption of resources. The application of a scientific method for prioritizing, planning and problem solving, such as LSS, results as a key factor to improve the longterm competitiveness of agricultural industries in global markets and increases the environmental quality of agricultural and agrofood products.

\section{References}

Brady J.E., Allen T.T., Six Sigma literature: a review and agenda for future research. Quality and Reliability Engineering International 2006, 22, 335-367.

Beccali M., Cellura M., Iudicello M., Mistretta M., Resource consumption and environmental impacts of the agrofood sector: life cycle assessment of italian citrusbased products. Environmental Management, 2009, 43(4) 707-24.

Brewer P.C., Six Sigma helps a company create a culture of accountability. Journal of Organizational Excellence, 2004, 23(3), 45-59.

Breyfogle III F.W., Implementing Six Sigma: Smarter Solutions Using Statistical Methods. Wiley, 1999, New York

Breyfogle F.W., Cupello J.M., Meadows B., Managing Six Sigma: A Practical Guide to Understanding, Assessing, and Implementing the Strategy that Yields Bottom-line Success. John Wiley\&Sons, 2001, Danvers.

Citti P., Arcidiacono G., Pratesi I., Six Sigma for Quality Management. Proc. of Quality, Reliability and Maintenance Conference, 2004, Oxford, UK.

Citti P., Delogu M., Giorgetti A., The use of statistical problem solving methods for Risk Assessment. Proc. of Int. Conf. on Innovation Technology to Empower Safety, Health and Welfare in Agriculture and Agro-food Systems, 2008, Ragusa, Italy.

Devane R., Integrating Lean Six Sigma and High-Performance Organizations: Leading the Charge Toward Dramatic, Rapid and Sustainable Improvement. Pfeiffer, 2004, San Francisco.

George M.L., Lean Six Sigma for Service. McGraw-Hill, 2003, New York.

George M.L., Lean Six Sigma: Combining Six Sigma Quality with Lean Production Speed. McGraw-Hill, 2002, New York.
Giorgetti A., Delogu M. The potential of Risk Assessment based on statistical approach. Proc. of ESREL 2009 The $19^{\text {th }}$ European Conference on Safety and Reliability, 2009, Prague, CZ.

Goh T.N., Xie M., Improving on the Six Sigma paradigm. The TQM Magazine, 2004, 16(4), 235-240.

Guo H., Application of Six Sigma Management in Agricultural Product Logistics. Proc. of The Eighth International Conference of Chinese Logistics and Transportation Professionals (ICCLTP), 2008, Chengdu, China, 3634-3640.

Harry M., Schroeder R., Six sigma: The breakthrough management strategy revolutionizing the world's top corporations. Currency/Doubleday, 2000, New York.

Ohno T., Toyota Production System. Productivity Press, 1988, Portland.

Pyzdek T., The Six Sigma Handbook. McGraw Hill, 2003, New York.

Raisinghani M.S., Six Sigma: Concept tools and applications. Industrial Management \& Data Systems, 2005, 105(4), 491-505.

Tylutki T.P., Fox D.G., Mooooving Toward Six Sigma. Quality Progress, 2002, 35(2), 34-41.

Tylutki T.P., Acan P.D., Fox D.G., Mcmahon M., Implementation of Nutrient Management Planning on a Dairy Farm. The Professional Animal Scientist, 2004, 20, 58-65.

\section{SUMMARY}

This paper describes the application of a Lean Six Sigma (LSS) project to a winemaking process in a high-quality, Italian winery. LSS is used to focus on the problem through a quantitative analysis of waste and quality performances. The LSS basic algorithm (called "DMAIC") helps to detect and quantify critical aspects of the process for transferring liquid used in the cellar. The improvement solution is developed and applied through the modification of the cellar system and the process procedure. The results obtained with this solution are shown and discussed in this paper, so too the long term reliability of the improved process analyzed. The results obtained by this case study can help to understand the importance of the LSS method to drive the improvement of agricultural and agrofood productions also in terms of environmental impact which is strongly connected to waste reduction.

Keywords: lean six sigma, process improvement, winemaking plant, winery, waste reduction, environmental impact, piping discharge. 
001_Bettini(572)_01 1-03-2011 14:42 Pagina 8

$\bigoplus$ 